DOI: 10.12731/wsd-2018-3-77-99

УДК 616.132.2-008.6

\title{
ВЛИЯНИЕ РЕАБИЛИТАЦИИ НА КАЧЕСТВО ЖИЗНИ БОЛЬНЫХ, ПЕРЕНЕСШИХ ОСТРЫЙ КОРОНАРНЫЙ СИНДРОМ С ЭКСТРЕННОЙ ЧТКА И СТЕНТИРОВАНИЕМ КОРОНАРНЫХ АРТЕРИЙ (г. КРАСНОЯРСК)
}

Аксютина Н.В., Шульман В.А., Никулина С.Ю., Беспалов А.В., Князева И.С., Мордовский В.С., Алданова Е.Е., Злаказов О.В., Чухломин Н.В., Красуля И.В., Кокоуров А.О., Чиняков Д.А., Гвоздева А.В., Кузнецова О.О., Севостьянова И.И.

Цель. Изучить изменение качества жизни больных, перенесших острый коронарнылй синдром (ОКС) с экстренной реваскуляризачией посредством ЧТКА и стентирования коронарных артерий (КА).

Материалы и методы. Включено 150 паџиентов с ОКС, ЧТКА и стентированием КА. 1 группа - 65 человек, направленных на 2 этап кардиореабилитации; 2 группа - 85 человек, отказавиихся от проведения 2 этапа кардиореабилитации. Пациенты прошли стандартное обследование и дополнительно тестирование по тесту-опроснику Бека и SF-36.

Результаты. Пациенты с полныл курсом кардиореабилитации имели статический значимылй прирост показателей здоровья (физический компонент здоровья после выписки 42,30 [38,25; 44,35] относительно через 6 месяцев 56,30 [51,85; 58,10], $p<0,001$; психологический компонент после выписки 42,80 [39,75; 50,20] относительно через 6 месяцев 56,70 [51,85; 57,20], $p<0,001)$. Во 2 группе такой закономерности нет. Подтверждено отрицательное влияние табакокурения на физический (r $=-0,629, p<0,05)$ и психологический $(r=-0,621, p<0,05)$ компоненты здоровья, и повыпенного уровня холестерина на физический ( $r=-0,424$, $p<0,05)$ и психологический $(r=-0,405, p<0,05)$ компоненты здоровья.

Заключение. Выявлена высокая значимость реабилитационных мероприятий у пациентов после стационарного лечения по поводу ОКС, ЧТКА и стентирования КА. При этом, из имеющихся факторов риска на качество реабилитационных мероприятий отрицательно влияет повьшенный уровень холестерина и курение. 
Siberian Journal of Life Sciences and Agriculture, Vol 10, №3, 2018

Ключевые слова: острый коронарный синдром; стентирование коронарных артерий; кардиореабилитачия; качество жизни; физический и психологический компоненты здоровья; опросник SF-36.

\title{
THE IMPACT OF REHABILITATION \\ ON QUALITY OF LIFE OF PATIENTS WITH ACUTE CORONARY SYNDROME WITH EMERGENCY REVASCULARIZATION BY PERCUTANEOUS TRANSLUMINAL CORONARY ANGIOPLASTY AND STENTING THE CORONARY ARTERIES (KRASNOYARSK)
}

\author{
Aksyutina N.V., Shulman V.A., Nikulina S.Y., Bespalov A.V., \\ Knyazeva I.S., Mordovsky V.S., Aldanova E.E., Zlakazov O.V., Chuhlomin \\ N.V., Krasulya I.V., Kokourov A.O., Chinyakov D.A., Gvozdeva A.V., \\ Kuznetsova O.O., Sevostyanova I.I.
}

Background. To study the dynamics in the quality of life of patients with acute coronary syndrome (ACS) with emergency revascularization by percutaneous transluminal coronary angioplasty and stenting the coronary arteries (CA).

Materials and methods. 150 patients with ACS, percutaneous transluminal coronary angioplasty and stenting the coronary arteries (CA) were included. 65 patients (group 1) performed all procedures of second phase of cardiac rehabilitation program. 85 patients (group 2), who refused of participation in rehabilitation program, were tested according to the test-questionnaire Beck and SF-36.

Results. Patients with a full course of rehabilitation program had a statically significant increase in health indicators (physical health component after discharge 42,30 [38,25; 44,35] in 6 months 56,30 [51,85; 5,810], $p<0,001$; psychological component after discharge 42,80 [39,75; 50,20] in 6 months $56,70[51,85 ; 57,20], p<0,001)$. In group 2 there was no such pattern noticed. Tobacco smoking influenced physical $(r=-0,629, p<0,05)$ and psychological $(r=-0,621, p<0,05)$ components of health negatively. Also increased cholesterol influenced physical $(r=-0,424, p<0,05)$ and psychological $(r=-0,405$, $p<0,05)$ components of health.

Conclusions. the high importance of rehabilitation program in patients after inpatient ACS treatment, percutaneous transluminal coronary angioplasty and stenting the coronary arteries was revealed. Increased cholesterol and smoking decrease the positive effect of rehabilitation. 
Keywords: acute coronary syndrome; coronary artery stenting; cardiac rehabilitation; quality of life; physical and psychological components of health; SF-36 questionnaire.

Около половины случаев смерти от заболеваний сердечно-сосудистой системы (ССС) приходится на долю ишемической болезни сердца (ИБС). Наиболее опасным является период обострения ИБС, клинические варианты которого объединяются термином острый коронарный синдром (ОКС) ввиду невозможности быстрого дифференциального диагноза между инфарктом миокарда (ИМ) или нестабильной стенокардией (НС) [1]. За последние годы в лечении больных ОКС появились не только новые направления медикаментозной терапии, но и значительно расширились возможности инвазивных вмешательств [2-4]. Широкое применение ЧКВ в клинической практике диктует необходимость разработки адекватного медицинского сопровождения не только до и во время, но и, что не менее важно, после выполнения мероприятий по восстановлению проходимости коронарных артерий. Важную роль в улучшении конечных результатов играет кардиореабилитация [5-12]. Выделяют три основных этапа, или фазы, кардиореабилитации: первая фаза кардиореабилитации (стационарная) проводится в стационаре; вторая (амбулаторная) фаза начинается после выписки и продолжается в кардиологическом санатории, диспансере, или, что значительно реже, в реабилитационном отделении самой клиники; третья фаза проводится во время дальнейшего наблюдения в поликлинике или специализированном диспансере, фактически длится всю жизнь и относится к вторичной сердечно-сосудистой профилактике [10]. В г. Красноярске трехэтапную систему реабилитации больных с ИМ внедрила профессор В.А. Опалева-Стеганцева. Однако, вторичная профилактика в виде кардиореабилитации по-прежнему недостаточно реализована в клинической практике [13-21]. Первый этап реабилитации проходят все пациенты в стационаре при отсутствии противопоказаний, а то, что касается второго этапа - существует несоответствие между вместимостью санаториев кардиологического профиля и нуждаемостью пациентов в прохождении кардиореабилитации. Поэтому, на данном этапе значительная роль уделяется дневным стационарам, реабилитационным центрам и кардиологическим диспансерам $[10,18]$. Расширение и усовершенствование программы реабилитации направлено на улучшение прогноза и качества жизни пациентов [13-16]. Одной из наиболее часто используемых шкал для оценки качества жизни пациентов 
является неспецифический опросник SF-36, включающий в себя оценку физического и психологического компонентов здоровья [21].

Учитывая чрезвычайную актуальность восстановительной медицины, нами было проведено исследование с целью изучить изменение качества жизни больных, перенесших ОКС с экстренной реваскуляризацией посредством ЧТКА и стентирования КА.

\section{Материал и методы исследования.}

В исследование включено 150 пациентов (98 мужчин и 52 женщины), госпитализированных в 1 кардиологическое отделение КГБУЗ «КМКБ № 20 им. И.С. Берзона» по поводу ОКС с проведенной экстренной реваскуляризацией посредством ЧТКА и стентирования КА. У 40 человек (26,67\%) диагностирован ОИМ с подъемом сегмента ST, у 48 (30,00 \%) ОИМ без подъема ST, у 62 (43,33 \%) - HC.

Первый этап кардиореабилитации (больничный) был проведен всем включенным в исследование пациентам. После чего пациенты были разделены на 2 группы: в первую группу вошло 65 пациентов, направленных на второй этап кардиореабилитации в «Профессорскую клинику КрасГМУ» или в «Центр современной кардиологии» после стационарного лечения; во вторую группу - 85 пациентов, отказавшихся от прохождения второго этапа кардиореабилитации. Медиана возраста пациентов первой группы $(63,00$ года $[58,00 ; 67,50])$ статистически значимо не отличалась от медианы возраста лиц второй группы $(67,00$ лет $[57,50 ; 74,00]), p>0,05$.

Критерии включения в исследование: впервые госпитализированные по поводу с ОКС; однососудистое поражение (стентирование 1 КА); клиника стенокардии напряжения около 5-и лет; гипертоническая болезнь в анамнезе; первично стентированные; без аортокоронарного шунтирования (АКШ) в анамнезе; стандартная терапия после выписки из стационара (два дезагреганта, статин, ингибитор АПФ или сартан, $\beta$-блокатор); жители г. Красноярска. Критерии исключения: наличие госпитальных осложнений (пароксизмальные нарушения ритма и проводимости, застойная XCH, кардиогенный шок); неконтролируемая артериальная гипертония с подъемом САД >190 мм.рт.ст. несмотря на гипотензивную терапию; наличие сахарного диабета; острые воспалительные заболевания и лихорадка; недавние эмболии; активный тромбофлебит; активный эндокардит, миокардит или перикардит; клапанные пороки, требующие хирургического лечения, в том числе умеренный или тяжелый аортальный стеноз; наличие депрессии (количество баллов по тест-опроснику Бека 9 и более). 
Включенным в исследование пациентам в стационаре проведены лабораторный и функциональные методы исследования согласно медикоэкономическим стандартам. При включении в исследование проводилось тестирование по тест-опроснику Бека для исключения скрытой депрессии. При выписке из стационара и через 6 месяцев после стационарного лечения всем пациентам оценивалось качество жизни (физический и психологический компоненты здоровья) посредством опросника SF-36. Количественные показатели физического и психологического компонентов здоровья рассчитывались индивидуально для каждого пациента, внося полученные данные в ходе анкетирования в программу расчета, встроенную в опросник online. Статистическая обработка материала осуществлялась с использованием прикладных программ “Excel”, STATISTICA FOR WINDOUS 7.0, IBM SPSS 20 по нижеперечисленным методикам: для качественных признаков использовался критерий $\chi^{2}$; корреляционный анализ проводился с использованием критерия Спирмена; количественные признаки оценивалась согласна критерию Манна-Уитни.

\section{Результаты исследования.}

После выписки из стационара показатели физического $(42,30[38,25$; $44,35])$ и психологического $(42,80[39,75 ; 50,20])$ компонентов здоровья у больных, направленных на кардиореабилитацию, статистически значимо не отличались от показателей физического $(40,10[33,20 ; 48,55])$ и психологического 44,50 [37,60; 53,60] компонентов здоровья пациентов, отказавшихся от кардиореабилитации, $\mathrm{p}>0,05$, (рис. 1).
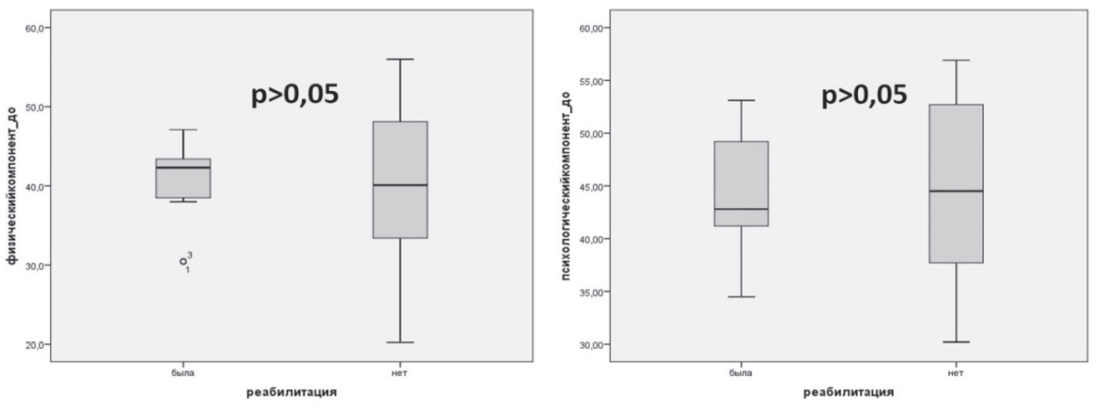

Примечание: Различия по исследуемым показателям рассчитаны с использованием критерия Манна-Уитни

Рис. 1. Физический и психологический компоненты здоровья после выписки из стационара 
Следует отметить, что у включенных в исследование пациентов за весь период наблюдения повторных госпитализаций по поводу ОКС не было, повторных коронарографий, стентирований не проводилось. Летальных исходов не наблюдалось.

У пациентов, прошедших кардиореабилитацию, через 6 месяцев отмечалось статистически значимое улучшение показателей здоровья при сравнении с показателями здоровья при выписке из стационара (медиана показателя физического компонента после выписки 42,30 [38,25; 44,35] относительно показателя через 6 месяцев 56,30 [51,85; 58,10], p<0,001), (медиана показателя психологического компонента после выписки 42,80 $[39,75 ; 50,20]$ относительно показателя через 6 месяцев $56,70[51,85$; 57,20], $p<0,001$ ), (рис. 2).
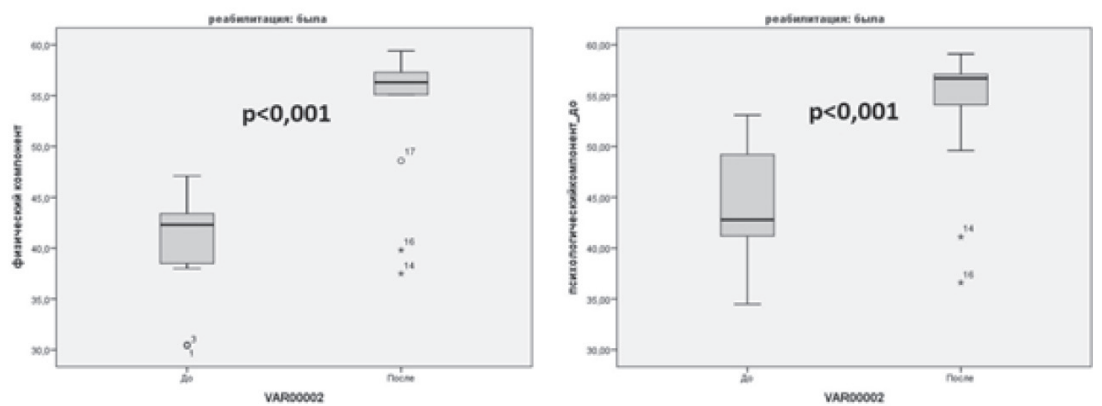

Примечание: Различия по исследуемым показателям рассчитаны с использованием критерия Манна-Уитни

Рис. 2. Физический и психологический компоненты здоровья прошедших кардиореабилитацию (после выписки и через 6 месяцев)

В группе пациентов, не прошедших кардиореабилитацию, такой закономерности не наблюдалось (физический компонент: 40,10 [33,20; $48,55]$ относительно $41,00[33,80 ; 48,00], p>0,05$ ), (психологический компонент 44,50 [37,60; 53,60] относительно 44,10 [38,60; 54,00], $p>0,05$ ), (рис. 3).

В группе пациентов, прошедших реабилитацию через 6 месяцев после выписки из стационара показатели физического компонента здоровья $(56,30[51,85 ; 58,10])$ были статистически значимо лучше, чем в группе без реабилитации $(41,00[33,80 ; 48,00]), p<0,001$. По психологическому компоненту отмечены такие же закономерности $(56,70[51,85 ; 57,20]$ относительно 44,10 [38,60; 54,00], $p<0,001$ ), (рис. 4). 

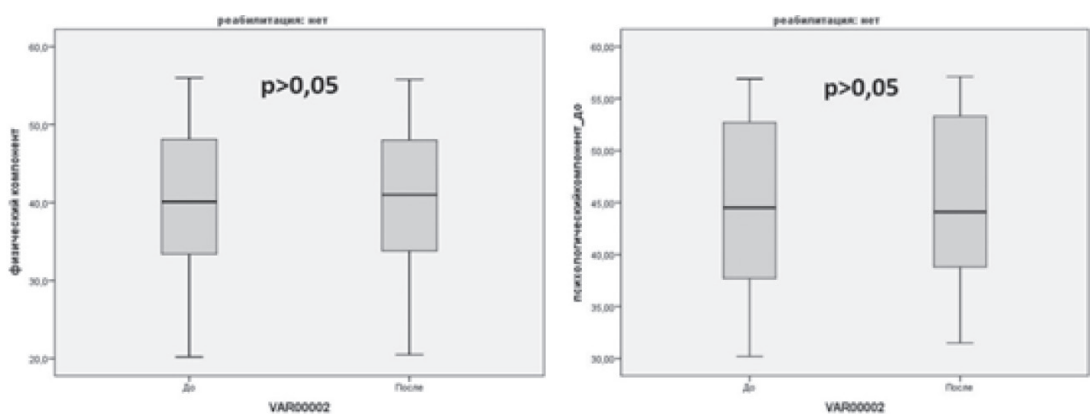

Примечание: Различия по исследуемым показателям рассчитаны с использованием критерия Манна-Уитни

Рис. 3. Физический и психологический компоненты здоровья пациентов без кардиореабилитации (после выписки и через 6 месяцев).
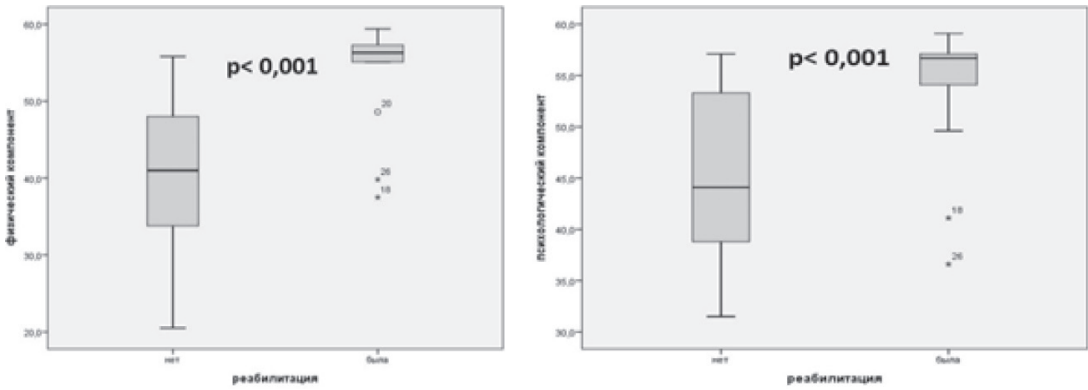

Примечание: Различия по исследуемым показателям рассчитаны с использованием критерия Манна-Уитни

Рис. 4. Физический и психологический компоненты здоровья у пациентов через 6 месяцев после стационарного лечения

Получены статистически значимые прямые корреляционные связи между проведенной кардиореабилитацией с физиологическим $(r=0,680$, $p<0,0001)$ и психологическим $(r=0,529, p<0,05)$ компонентами здоровья, что говорит о положительном влиянии реабилитационных мероприятий на качество жизни больных. Физический компонент здоровья в свою очередь имеет статистически значимую прямую корреляционную связь с психологическим компонентом ( $r=0,887, p<0,0001)$, (рис. 5).

Из имеющихся факторов риска, повышенный уровень холестерина определялся в группе пациентов без реабилитации статистически значимо чаще, чем у пациентов, прошедших реабилитацию $(80(94,12 \%)$ от- 
носительно 40 (62,50\%), $p<0,0001)$. Помимо этого, курящих пациентов в группе без кардиореабилитации было статистически значимо больше (45 (52,94\%) относительно 15 (23,08\%), $p<0,0001)$, (рис. 6, рис. 7$)$.

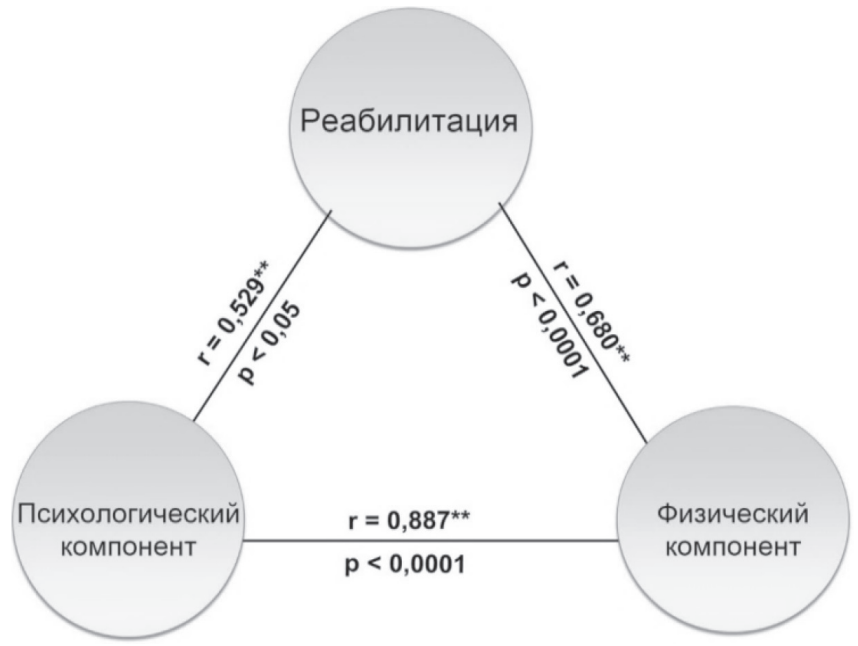

Примечание: Корреляционный анализ проводился с использованием критерия Спирмена

Рис. 5. Влияние кардиореабилитации на физический и психологический компоненты здоровья

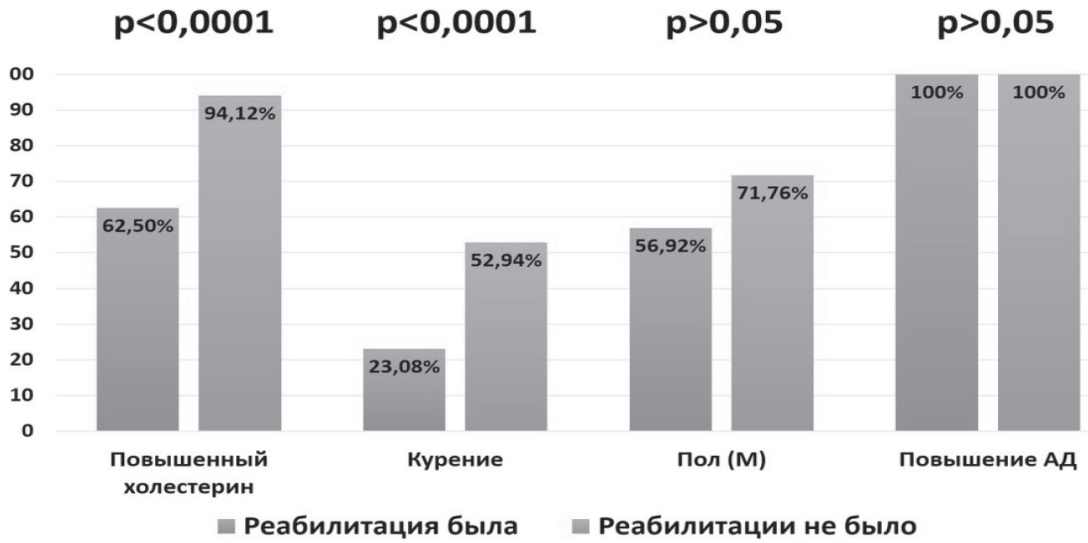

Примечание: Различия по исследуемым показателям рассчитаны с использованием критерия $\chi 2$.

Рис. 6. Корригируемые и не корригируемые факторы риска (повышение холестерина, курение, мужской пол, повышение АД) 


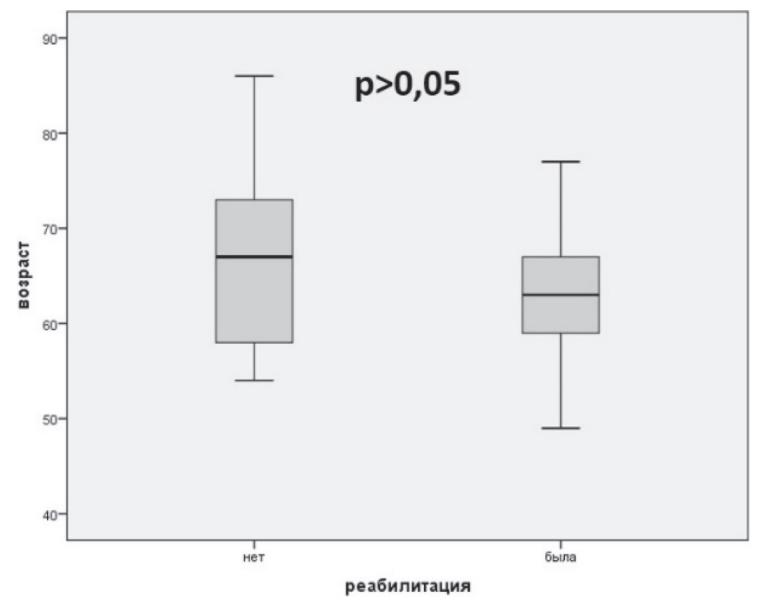

Примечание: Различия по исследуемым показателям рассчитаны с использованием критерия Манна-Уитни

Рис. 7. Не корригируемый фактор риска (возраст)

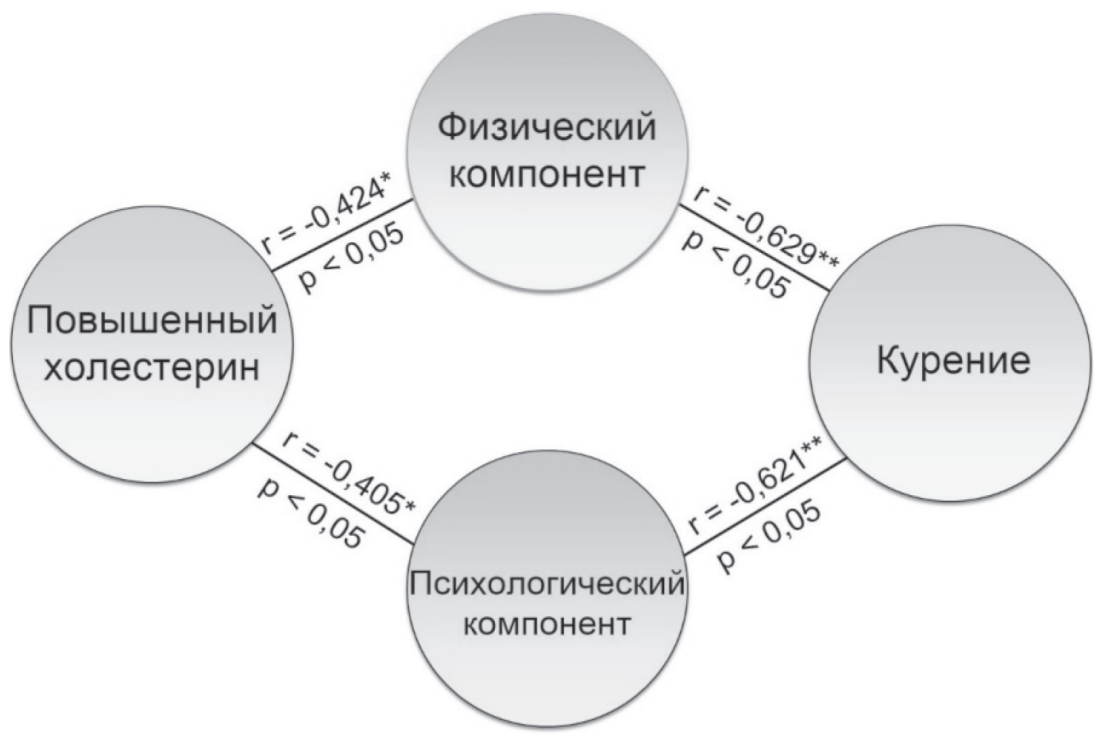

Примечание: Корреляционный анализ проводился с использованием критерия Спирмена

Рис. 8. Связь физического и психологического компонентов здоровья с повышенным уровнем холестерина и курением 
Физический и психологический компоненты здоровья имеют статистически значимые отрицательные корреляционные связи с курением (с физическим компонентом $(\mathrm{r}=-0,629, \mathrm{p}<0,05)$; с психологическим компонентом $(\mathrm{r}=-0,621, \mathrm{p}<0,05)$ и повышением уровня холестерина (с физическим компонентом $(\mathrm{r}=-0,424, \mathrm{p}<0,05)$; с психологическим компонентом $(\mathrm{r}=-0,405, \mathrm{p}<0,05)$, (рис. 8), что свидетельствует об отрицательном влиянии курения и повышенного уровня холестерина на качество реабилитационных мероприятий.

\section{Выводы:}

1. Выявлена высокая значимость реабилитационных мероприятий у пациентов после стационарного лечения по поводу ОКС, ЧТКА и стентирования КА;

2. Из имеющихся факторов риска, на качество реабилитационных мероприятий отрицательно влияет повышенный уровень холестерина и курение.

\section{Обсуждение результатов исследования.}

Исследований, направленных на дальнейшее наблюдение с оценкой качества жизни пациентов, госпитализированных по поводу ОКС с экстренно проведенной ЧТКА и стентированием КА в г. Красноярске до настоящего времени, не проводилось. Результаты нашего исследования, показавшего высокую значимость кардиореабилитации в улучшении качества жизни, сопоставимы с результатами отечественных и зарубежных исследований $[7,22-25]$. Учитывая высокую значимость кардиореабилитации в улучшении качества жизни пациентов, перенесших ОКС с экстренной ЧТКА и стентированием КА, мы планируем продлить наблюдение за включенными в исследование людьми, увеличить численность групп путем включения новых пациентов, расширения критериев включения в исследование. Помимо этого, планируется оценить изменение качества жизни в зависимости от прикрепления пациента к определенной поликлинике города. Полученные результаты позволят судить о качестве реабилитации, разобраться с недостатками амбулаторно-поликлинической помощи населению г. Красноярска. Усовершенствование программы кардиореабилитации позволит обеспечить сбалансированность объемов государственных гарантий оказания населению медицинской помощи, повысить эффективность использования коечного фонда, а также качество и трудоспособный период жизни населения страны за счет снижения инвалидности. 


\section{Список литературы}

1. Аглуллина Э.И. Острый коронарный синдром: от диагностики к оптимизации лечения // Вестник современной клинической медицины. 2013. № 5. C. 91-94.

2. Barriers to Outpatient Hospital-Based Cardiac Rehabilitation in Korean Patients With Acute Coronary Syndrome / Im H.W., Baek S., Jee S., Ahn J.M., Park M.W., Kim W.S. // Annals of rehabilitation medicine. 2018. vol. 42, № 1. P. 154-165. doi: 10.5535/arm.2018.42.1.154.

3. Затейщиков В.А., Бражник В.А. Тактика ведения больных острым коронарным синдромом. Модуль. М.: ГЭОТАР-Медиа, 2017. URL: http://www. rosmedlib.ru/book/07-MOD-2101.html (дата обращения: 21.05.2018).

4. Диагностика и лечение больных острым инфарктом миокарда с подъемом сегмента ST электрокардиограммы // Кардиологический вестник. 2014. № $4.59 \mathrm{c}$.

5. Кардиоваскулярная профилактика 2017 / Российское кардиологическое общество; Национальное общество профилактической кардиологии; Российское общество профилактики неинфекционных заболеваний. М., 2017. 289 с. URL: http://www.scardio.ru/content/Guidelines/project/Proekt_Kardiovascular_ prof_2017.pdf (дата обращения: 21.05.2018).

6. Work-related outcome after acute coronary syndrome: Implications of complex cardiac rehabilitation in occupational medicine / Lamberti M., Ratti G., Gerardi D., Capogrosso C., Ricciardi G., Fulgione C. // International Journal of Occupational Medicine and Environmental Health. 2016. vol. 29, № 4. P. 649-57. doi: 10.13075/ijomeh.1896.00643.

7. Cardiac rehabilitation in patients with acute coronary syndrome with primary percutaneous coronary intervention is associated with improved 10-year survival / Sunamura M., Ter Hoeve N., van den Berg-Emons R.J., Boersma E., van Domburg R.T., Geleijnse M.L. // European heart journal. Quality of care \& clinical outcomes. 2018. doi: 10.1093/ehjqcco/qcy001.

8. Аронов Д.М. Основы кардиореабилитации. Модуль. М.: ГЭОТАР-Медиа, 2016. URL: http://www.rosmedlib.ru/book/07-MOD-2003.html (дата обращения: 21.05.2018).

9. Бокерия Л.А., Аронов Д.М. Российские клинические рекомендации. Коронарное шунтирование больных ишемической болезнью сердца: реабилитация и вторичная профилактика // CardioСоматика. 2016. Т. 7, № 3-4. С. 5-71.

10. Трехэтапная система кардиореабилитации пациентов, перенесших сосудистое событие - инфаркт миокарда и/или стентирование коронарных артерий / Усачева Е.В., Щербаков Д.В., Нелидова А.В., Замахина О.В., Су- 
кончик А.О., Кузнецова В.В., Шишкина А.А. // Современные проблемы науки и образования. 2016. № 4. URL: http://science-education.ru/ru/article/ view? id=24908 (дата обращения: 23.05.2018).

11. Cardiac Rehabilitation Fitness Changes and Subsequent Survival / De Schutter A., Kachur S., Lavie C.J., Menezes A., Shum K.K., Bangalore S., Arena R., Milani R.V. // European heart journal. Quality of care \& clinical outcomes. 2018. doi: 10.1093/ehjqcco/qcy018.

12. Бубнова М.Г. Реабилитация больных после острого инфаркта миокарда. Модуль. М.: ГЭОТАР-Медиа, 2016. URL: http://www.rosmedlib.ru/ book/07-MOD-2102.html (дата обращения: 23.05.2018).

13. Качество жизни больных с постинфарктной аневризмой левого желудочка до и после хирургического лечения по методике D. Cooley и V. Dor / Поляков В.П., Максимова С.В., Семагин А.П., Неровный Д.Г. // Грудная и сердечно-сосудистая хирургия. 2005. № 1. С. 45-49.

14. Объективизация оценки качества жизни больных ишемической болезнью сердца / Осипов Д.А., Рождественская Т.В., Кром И.Л., Ребров А.П. // Саратовский научно-медицинский журнал. 2010. Т. 6, № 3. С. 585-588.

15. Study protocol for the World Health Organization project to develop a Quality of Life assessment instrument // Quality of Life Research. 1993. vol. 2, № 2. P. 153-158.

16. Качество жизни пациентов в зависимости формы острого коронарного синдрома без подъёма сегмента ST / Айрапетян М.А., Лучинкина Е.Е., Гордеев И.Г., Таратухин Е.О. // Российский кардиологический журнал. 2017. № 8 (148). C. 31-35.

17. Quality of life among Patients with Acute Coronary Syndrome in Malaysia / Azmi S., Goh A., Fong A., Anchah L. // Value Health Regional Issues. 2015. № 6. P. 80-83. doi: 10.1016/j.vhri.2015.03.015.

18. Аронов Д.М., Бубнова М.Г. Проблемы внедрения новой системы кардиореабилитации в России // Российский кардиологический журнал. 2013. № 4. C. 14-22. doi:10.15829/1560-4071-2013-4-14-22

19. Андреева Т.В., Светлакова Л.В., Сыромятникова Л.И. Кардиореабилитация больных с острым коронарным синдромом в условиях санатория-курорта «Усть-Качка». Значение лечебной физкультуры // Пермский медицинский журнал. 2015. Т. 32, № 5. С. 112-119.

20. Реабилитация и вторичная профилактика у больных, перенесших острый инфаркт миокарда с подъемом сегмента ST. Российские клинические рекомендации / Общероссийская общественная организация Российское общество кардиосоматической реабилитации и вторичной профилактики, Российское клинические рекомендации. М., 2014. 95 с. 
21. Нагибина Ю.В., Захарова Л.А. Медико-социальные особенности больных ишемической болезнью сердца и качество жизни // Российский кардиологический журнал. 2017. № 3. С. 155-159. doi:10.15829/1560-4071-2017-3$155-159$.

22. Динамика сократительной функции сердца в процессе трехмесячного амбулаторного этапа кардиореабилитации больных, перенесших острый коронарный синдром / Довгалюк Ю.В., Мишина И.Е., Архипова С.Л., Суханова Д.С., Белова В.В. // Актуальные вопросы профилактики, ранней диагностики, лечения и медицинской реабилитации больных с неинфекционными заболеваниями и травмами : материалы IV Межрегиональной научно-практической конференции Центрального федерального округа с международным участием для специалистов, оказывающих помощь по медицинской реабилитации. Иваново, 2016. С. 59-60.

23. Лямина Н.П., Котельникова Е.В, Носенко А.Н. Современные подходы к формированию врачебных решений в кардиореабилитации // Современные проблемы науки и образования. 2011. № 4. URL: http://scienceeducation.ru/ru/article/view?id=4722 (дата обращения: 24.05.2018).

24. Физические тренировки в кардиореабилитации и профилактике у больных ИБС после чрескожных коронарных вмешательств: границы эффективности и безопасности / Лямина Н.П., Карпова Э.С., Котельникова Е.В., Бизяева Е.А. // Российский кардиологический журнал. 2014. № 6. С. 93-98.

25. Зубарева О.А. Типы отношения к болезни у пациентов с разными формами ишемической болезни сердца в остром периоде // В мире научных открытий. 2015. № 1. doi: https://doi.org/10.12731/wsd-2015-1-30

\section{References}

1. Aglullina E.I. Ostryy koronarnyy sindrom: ot diagnostiki k optimizatsii lecheniya [Acute coronary syndrome: from diagnosis to treatment optimization]. Vestnik sovremennoi klinicheskoi mediciny [The Bulletin of Contemporary Clinical Medicine], 2013, no. 5. pp. 91-94.

2. Im H.W., Baek S., Jee S., Ahn J.M., Park M.W., Kim W.S. Barriers to Outpatient Hospital-Based Cardiac Rehabilitation in Korean Patients With Acute Coronary Syndrome. Annals of rehabilitation medicine, 2018, vol. 42, no. 1, pp. 154-165. doi: 10.5535/arm.2018.42.1.154.

3. Zateeyshchikov D.A., Brazhnik V.A. Taktika vedeniya bol'nykh ostrym koronarnym sindromom. Modul' [Tactics of management of patients with acute coronary syndrome. Module]. Moscow: GEOTAR-Media, 2017. http://www. rosmedlib.ru/book/07-MOD-2101.html (accessed May 21, 2018). 
4. Diagnostika i lechenie bol'nykh ostrym infarktom miokarda s pod"emom segmenta ST elektrokardiogrammy [Diagnosis and treatment of patients with acute myocardial infarction with elevation of the ST segment of the electrocardiogram]. Kardiologicheskij Vestnik, 2014, no. 4, 59 p.

5. Kardiovaskulyarnaya profilaktika 2017 [Cardiovascular Prevention 2017] / Russian Cardiology Society, National Society of Preventive Cardiology, Russian Society for the Prevention of Noncommunicable Diseases. Moscow, 2017. 289 p. http://www.scardio.ru/content/Guidelines/project/Proekt_Kardiovascular_prof_2017.pdf (accessed May 21, 2018).

6. Lamberti M., Ratti G., Gerardi D., Capogrosso C., Ricciardi G., Fulgione C. Work-related outcome after acute coronary syndrome: Implications of complex cardiac rehabilitation in occupational medicine. International Journal of Occupational Medicine and Environmental Health, 2016, vol. 29, no. 4, pp. 649-57. doi: 10.13075/ijomeh.1896.00643.

7. Sunamura M., Ter Hoeve N., van den Berg-Emons R.J., Boersma E., van Domburg R.T., Geleijnse ML. Cardiac rehabilitation in patients with acute coronary syndrome with primary percutaneous coronary intervention is associated with improved 10-year survival. European heart journal. Quality of care \& clinical outcomes, 2018. doi: 10.1093/ehjqcco/qcy001.

8. Aronov D.M. Osnovy kardioreabilitatsii. Modul' [Basis of cardiac rehabilitation. Module]. Moscow: GEOTAR-Media, 2016. http://www.rosmedlib.ru/ book/07-MOD-2003.html (accessed May 21, 2018).

9. Bokeriya L.A., Aronov D.M. Rossiyskie klinicheskie rekomendatsii. Koronarnoe shuntirovanie bol'nykh ishemicheskoy bolezn'yu serdtsa: reabilitatsiya i vtorichnaya profilaktika [Russian clinical guidelines Coronary artery bypass grafting in patients with ischemic heart disease: rehabilitation and secondary prevention]. CardioSomatics, 2016, vol. 7, no. 3-4, pp. 5-71.

10. Usacheva E.V., Scherbakov D.V., Nelidova A.V., Zamakhina O.V., Sukonchik A.O., Kuznetsova V.V., Shishkina A.A. Trekhetapnaya sistema kardioreabilitatsii patsientov, perenesshikh sosudistoe sobytie - infarkt miokarda i/ili stentirovanie koronarnykh arteriy [Three-phase system cardiorehabilitation patients undergoing vascular events - myocardial infarction and/or coronary artery stenting]. Sovremennye problemy nauki i obrazovaniya [Modern problems of science and education], 2016, no. 4. http://science-education.ru/ru/article/ view? $\mathrm{id}=24908$ (accessed May 21, 2018).

11. De Schutter A., Kachur S., Lavie C.J., Menezes A., Shum K.K., Bangalore S., Arena R., Milani R.V. Cardiac Rehabilitation Fitness Changes and Subsequent Survival. European heart journal. Quality of care \& clinical outcomes, 2018. doi: 10.1093/ehjqcco/qcy018. 
12. Bubnova M.G. Reabilitatsiya bol'nykh posle ostrogo infarkta miokarda. Mod$u l$ '[Rehabilitation of patients after acute myocardial infarction. Module]. Moscow: GEOTAR-Media, 2016. http://www.rosmedlib.ru/book/07-MOD-2102. html (accessed May 21, 2018).

13. Polyakov V.P., Maksimova S.V., Semagin A.P., Nerovnyi D.G. Kachestvo zhizni bol'nykh s postinfarktnoy anevrizmoy levogo zheludochka do i posle khirurgicheskogo lecheniya po metodike [Life quality in patients with postinfarct aneurysm of the left ventricle before and after surgical treatment by the procedure developed by D. Cooley and V. Dor]. Grudnaya i serdechno-sosudistaya khirurgiya [Thoracic and cardiovascular surgery], 2005, no. 1, pp. 45-49.

14. Osipov D.A., Rozhdestvenskaya T.V., Krom I.L., Rebrov A.P. Ob"ektivizatsiya otsenki kachestva zhizni bol'nykh ishemicheskoy bolezn'yu serdtsa [Objective evaluation of life quality of patients with ischemic heart disease]. Saratovskiy nauchno-meditsinskiy zhurnal [Saratov Journal of Medical Scientific Research], 2010, vol. 6, no. 3, pp. 585-588.

15. Study protocol for the World Health Organization project to develop a Quality of Life assessment instrument. Quality of Life Research, 1993, vol. 2, no. 2, pp. 153-158.

16. Ayrapetian M.A., Luchinkina E.E., Gordeev I.G., Taratukhin E.O. Kachestvo zhizni patsientov v zavisimosti ot pola i formy ostrogo koronarnogo sindroma bez pod"ema segmenta ST. [Life quality of patients according to gender and the form of non-st-elevation acute coronary syndrome]. Russian Journal of Cardiology, 2017, no. 8, pp. 31-35. doi: 10.15829/1560-4071-2017-8-31-35.

17. Azmi S., Goh A., Fong A., Anchah L. Quality of life among Patients with Acute Coronary Syndrome in Malaysia. Value Health Regional Issues. 2015, no. 6, pp. 80-83. doi: 10.1016/j.vhri.2015.03.015.

18. Aronov D.M., Bubnova M.G. Problemy vnedreniya novoy sistemy kardioreabilitatsii v Rossii [Challenges of the implementation of a new cardiac rehabilitation system in Russia]. Russian Journal of Cardiology. 2013, no. 4, pp. 14-22. doi: 10.15829/1560-4071-2013-4-14-22

19. Andreeva T.V., Svetlakova L.V., Syromyatnikova L.I. Kardioreabilitatsiya bol'nykh s ostrym koronarnym sindromom v usloviyakh sanatoriya-kurorta «Ust'-Kachka». Znachenie lechebnoy fizkul'tury [Cardiorehabilitation of patients with acute coronary syndrome in conditions of health resort "Ust-Kachka". Significance of therapeutic physical training]. Perm Medical Journal, 2015, vol, 32, no. 5, pp. 112-119.

20. Reabilitatsiya i vtorichnaya profilaktika u bol'nykh, perenesshikh ostryy infarkt miokarda s pod"emom segmenta ST. Rossiyskie klinicheskie rekomendatsii [Rehabilitation and secondary prophylaxis in patients who underwent acute myocardial infarction with ST segment elevation. Russian Clinical Recommen- 
dations] / All-Russian Public Organization Russian Society of Cardiosomal Rehabilitation and Secondary Prevention, Russian Clinical Recommendations. Moscow, 2014. 95 p.

21. Nagibina Y.V., Zakharova L.A. Medico-Sotsial"nye osobennosti bol"nykh ishemicheskoy bolezn"yu serdtsa i kachestvo zhizni [Life quality, medcal and social characteristics of coronary heart disease patients]. Russian Journal of Cardiology, 2017, № 3, pp. 155-159. doi: 10.15829/1560-4071-2017-3-155-159.

22. Dovgaljuk Ju.V., Mishina I.E., Arhipova S.L., Suhanova D.S., Belova V.V. Dinamika sokratitel'noj funkcii serdca $\mathrm{v}$ processe trehmesjachnogo ambulatornogo jetapa kardioreabilitacii bol'nyh, perenesshih ostryj koronarnyj sindrom [The dynamics of the contractile function of the heart in the process a three-month outpatient phase of cardiorehabilitation of patients with acute coronary syndrome]. Aktual'nye voprosy profilaktiki, rannej diagnostiki, lechenija i medicinskoj reabilitacii bol'nyh s neinfekcionnymi zabolevanijami i travmami : materialy IV Mezhregional'noj nauchno-prakticheskoj konferencii Central'nogo federal'nogo okruga s mezhdunarodnym uchastiem dlja specialistov, okazyvajushhih pomoshh' po medicinskoj reabilitacii [Topical issues of prevention, early diagnosis, treatment and medical rehabilitation of patients with non-communicable diseases and injuries : proceedings of the IV inter-regional scientific-practical conference of the Central Federal district with international participation of specialists that provide assistance for medical rehabilitation]. Ivanovo, 2016, pp. 59-60.

23. Lyamina N.P., Kotelnikova E.V., Nosenko A.N. Modern approach of medical decisions formation in cardiorehabilitation. Sovremennye problemy nauki i obrazovaniya [Modern problems of science and education], 2011, no. 4. http://science-education.ru/ru/article/view?id=4722 (дата обращения: 24.05.2018).

24. Lyamina N.P., Karpova E.S., Kotelnikova E.V., Bizyaeva E.A. Fizicheskie trenirovki v kardioreabilitacii i profilaktike u bol"nyh IBS posle chreskozhnyh koronarnyh vmeshatel"stv: granicy jeffektivnosti i bezopasnosti [Physical training in the rehabilitation and prevention in patients with ischemic heart disease after percutaneous coronary interventions: the borders of efficiency and safety]. Russian Journal of Cardiology, 2014, no. 6, pp. 93-98.

25. Zubareva O.A. Tipy otnoshenija $\mathrm{k}$ bolezni u pacientov s raznymi formami ishemicheskoj bolezni serdca $\mathrm{v}$ ostrom periode [Types of attitude to the disease in patients with different forms of acute coronary heart disease]. V mire naučnych otkrytij [Siberian Journal of Life Sciences and Agriculture], 2015, no. 1. doi: https://doi.org/10.12731/wsd-2015-1-30. 


\section{ДАННЫЕ ОБ АВТОРАХ}

Аксютина Наталья Валерьевна, д.м.н., доцент кафедры внутренних болезней №1

Федеральное государственное бюджетное образовательное учреждение высшего образования «Красноярский государственный медииинский университет имени профессора В.Ф. Войно-Ясенеикого» Министерства здравоохранения Российской Федерации ул. Партизана Железняка, 1, г. Красноярск, 660022, Российская Федерачия aks-n-v@yandex.ru

Шульман Владимир Абрамович, д.м.н., профессор кафедры внутренних болезней №1

Федеральное государственное бюджетное образовательное учреждение высшего образования «Красноярский государственный медииинский университет имени профессора В.Ф. Войно-Ясенеикого» Министерства здравоохранения Российской Феде рациии

ул. Партизана Железняка, 1, г. Красноярск, 660022, Российская Федераиия

shulman36@mail.ru

Никулина Светлана Юрьевна, д.м.н., профессор, заведующая кафедрой внутренних болезней №1

Федеральное государственное бюджетное образовательное учреждение выстего образования «Красноярский государственный медицинский университет имени профессора В.Ф. Войно-Ясенеикого» Министерства здравоохранения Российской Федерации ул. Партизана Железняка, 1, г. Красноярск, 660022, Российская Федерация nicoulina@mail.ru

\section{Беспалов Андрей Владимирович, врач-хирург}

Краевое государственное бюджетное учреждение здравоохранения «Красноярская городская поликлиника № 4

ул. Партизана Железняка, 1, г. Красноярск, 660022, Российская Федераиия

farsajin@yandex.ru 


\section{Князева Ирина Сергеевна, студент}

Федеральное государственное бюджетное образовательное учреждение высшего образования «Красноярский государственный медииинский университет имени профессора В.Ф. Войно-Ясенеикого» Министерства здравоохранения Российской Федерации ул. Партизана Железняка, 1, г. Красноярск, 660022, Российская Федераиия vopros1211@yandex.ru

\section{Мордовский Василий Сергеевич, ординатор}

Федеральное государственное бюджетное образовательное учреждение высшего образования «Красноярский государственный медицинский университет имени профессора В.Ф. Войно-Ясенеикого» Министерства здравоохранения Российской Федерачии ул. Партизана Железняка, 1, г. Красноярск, 660022, Российская Федераиия vasek220@mail.ru

\section{Алданова Елена Евгеньевна, аспирант}

Федеральное государственное бюджетное образовательное учреждение высшего образования «Красноярский государственный медицинский университет имени профессора В.Ф. Войно-Ясенеикого» Министерства здравоохранения Российской Федераиии ул. Партизана Железняка, 1, г. Красноярск, 660022, Российская Федераиия alenka21121@mail.ru

Злаказов Олег Владимирович, к.м.н., начальник медицинского управления - проректор Федеральное государственное бюджетное образовательное учреждение высшего образования «Красноярский государственный медицинский университет имени профессора В.Ф. Войно-Ясенеикого» Министерства здравоохранения Российской Федерачии ул. Партизана Железняка, 1, г. Красноярск, 660022, Российская Федераиия zlak@mail.ru

\section{Чухломин Никита Васильевич, студент}

Федеральное государственное бюджетное образовательное учреждение высшего образования «Красноярский государственный 
медицинский университет имени профессора В.Ф. Войно-Ясенеикого» Министерства здравоохранения Российской Федерации ул. Партизана Железняка, 1, г. Красноярск, 660022, Российская Федераиия

kijke_1995@mail.ru

\section{Красуля Иван Владимирович, студент}

Федеральное государственное бюджетное образовательное учреждение высшего образования «Красноярский государственный медицинский университет имени профессора В.Ф. Войно-Ясенеикого» Министерства здравоохранения Российской Федерации ул. Партизана Железняка, 1, г. Красноярск, 660022, Российская Федерация Ivan-kras00@mail.ru

\section{Кокоуров Антон Олегович, студент}

Федеральное государственное бюджетное образовательное учреждение выстего образования «Красноярский государственный медииинский университет имени профессора В.Ф. Войно-Ясенеикого» Министерства здравоохранения Российской Федерации ул. Партизана Железняка, 1, г. Красноярск, 660022, Российская Федераиия kyuubiqwenking@gmail.com

\section{Чиняков Дмитрий Анатольевич, студент}

Федеральное государственное бюджетное образовательное учреждение высшего образования «Красноярский государственный медицинский университет имени профессора В.Ф. Войно-Ясенеикого» Министерства здравоохранения Российской Федерации ул. Партизана Железняка, 1, г. Красноярск, 660022, Российская Федерация

dmitrii.chinyakov@mail.ru

\section{Гвоздева Анастасия Владимировна, студент}

Федеральное государственное бюджетное образовательное учреждение высшего образования «Красноярский государственный медииинский университет имени профессора В.Ф. Войно-Ясенеикого» Министерства здравоохранения Российской Федерации 
ул. Партизана Железняка, 1, г. Красноярск, 660022, Российская Федераичи

Nastenka-rin.5824@mail.ru

Кузнецова Оксана Владимировна, к.м.н., доцент кафедра кардиологии, функциональной и клинико-лабораторной диагностики ИПО Федеральное государственное бюджетное образовательное учреждение выстего образования «Красноярский государственный медицинский университет имени профессора В.Ф. Войно-Ясенецкого» Министерства здравоохранения Российской Федерачии ул. Партизана Железняка, 1, г. Красноярск, 660022, Российская Федераичи isachenko102@inbox.ru

\section{Севостьянова Ирина Игоревна, студент}

Федеральное государственное бюджетное образовательное учреждение высшего образования «Красноярский государственный медицинский университет имени профессора В.Ф. Войно-Ясенеикого» Министерства здравоохранения Российской Федераиии ул. Партизана Железняка, 1, г. Красноярск, 660022, Российская Федераиия

Irisha94@inbox.ru

\section{DATA ABOUT THE AUTHORS}

Aksyutina Natalya Valeryevna, MD, Associate Professor Department of Internal Diseases

Prof. V.F. Voino-Yasenetsky Krasnoyarsk State Medical University

1, Partizan Zheleznyaka Str., Krasnoyarsk, 660022, Russian Federation

aks-n-v@yandex.ru

SPIN-code: 5028-3792

ORCID: orcid.org/0000-0002-4856-2729

ResearcherID: F-3846-2016

Scopus Author ID: 55671852900

Shulman Vladimir Abramovich, MD, Professor Department of internal Diseases Prof. V.F. Voino-Yasenetsky Krasnoyarsk State Medical University 1, Partizan Zheleznyaka Str., Krasnoyarsk, 660022, Russian Federation 
shulman36@mail.ru

SPIN-code: 3845-0004

Scopus Author ID: 7003452847

Nikulina Svetlana Yurievna, MD, Professor, Head of the Department of Internal Diseases

Prof. V.F. Voino-Yasenetsky Krasnoyarsk State Medical University

1, Partizan Zheleznyaka Str., Krasnoyarsk, 660022, Russian Federation nicoulina@mail.ru

SPIN-code: 1789-3359

ORCID: 0000-0002-6968-7627

ResearcherID: $N$-7054-2014

Scopus Author ID: 6603731700

Bespalov Andrey Vladimirovich, Surgeon

Regional state budget health care institution «Krasnoyarsk city polyclinic № 4»

17, Kurchatov Str., Krasnoyarsk, 660062, Russian Federation farsajin@yandex.ru

Knyazeva Irina Sergeevna, Student

Prof. V.F. Voino-Yasenetsky Krasnoyarsk State Medical University

1, Partizan Zheleznyaka Str., Krasnoyarsk, 660022, Russian Federation vopros1211@yandex.ru

ORCID: 0000-0001-5147-5872

ResearcherID: $K-7042-2018$

Mordovsky Basiliy Sergeyevich, Assistant Doctor

Prof. V.F. Voino-Yasenetsky Krasnoyarsk State Medical University

1, Partizan Zheleznyaka Str., Krasnoyarsk, 660022, Russian Federation vasek220@mail.ru

SPIN-code: 7732-2117

ORCID: 0000-0001-9666-2487

ResearcherID: K-7244-2018

Aldanova Elena Evgenevna, Graduate Student

Prof. V.F. Voino-Yasenetsky Krasnoyarsk State Medical University

1, Partizan Zheleznyaka Str., Krasnoyarsk, 660022, Russian Federation 
alenka21121@mail.ru

Scopus Author ID: 56700219700

Zlakazov Oleg Vladimirovich, Ph.D., Head of Medical Department

Prof. V.F. Voino-Yasenetsky Krasnoyarsk State Medical University

1, Partizan Zheleznyaka Str., Krasnoyarsk, 660022, Russian Federation zlak@mail.ru

SPIN-code: $7788-7916$

ORCID: 0000-0002-3295-2124

ResearcherID: $K-7253-2018$

Chuhlomin Nikita Vasilyevich, Student

Prof. V.F. Voino-Yasenetsky Krasnoyarsk State Medical University

1, Partizan Zheleznyaka Str., Krasnoyarsk, 660022, Russian Federation

E-mail:kijke_1995@mail.ru

ORCID: 0000-0003-3697-8636

ResearcherID: K-7135-2018

Krasulya Ivan Vladimirovich, Student

Prof. V.F. Voino-Yasenetsky Krasnoyarsk State Medical University

1, Partizan Zheleznyaka Str., Krasnoyarsk, 660022, Russian Federation Ivan-kras00@mail.ru

ORCID: 0000-0002-8045-9000

Kokourov Anton Olegovich, Student

Prof. V.F. Voino-Yasenetsky Krasnoyarsk State Medical University

1, Partizan Zheleznyaka Str., Krasnoyarsk, 660022, Russian Federation

kyuubiqwenking@gmail.com

ORCID: 0000-0003-3746-0302

Chinyakov Dmitry Anatolyevich, Student

Prof. V.F. Voino-Yasenetsky Krasnoyarsk State Medical University

1, Partizan Zheleznyaka Str., Krasnoyarsk, 660022, Russian Federation

dmitrii.chinyakov@mail.ru

ORCID: 0000-0002-4914-3980

ResearcherID: K-5541-2018 
Gvozdeva Anastasia Vladimirovna, Student

Prof. V.F. Voino-Yasenetsky Krasnoyarsk State Medical University

1, Partizan Zheleznyaka Str., Krasnoyarsk, 660022, Russian Federation

Nastenka-rin.5824@mail.ru

ORCID: 0000-0002-4657-6780

ResearcherID: $K-7155-2018$

Kuznetsova Oksana Olegovna, Ph.D., Associate Professor Department of Cardiology, Functional and Clinical-Laboratory Diagnostics and Postgraduate Education

Prof. V.F. Voino-Yasenetsky Krasnoyarsk State Medical University

1, Partizan Zheleznyaka Str., Krasnoyarsk, 660022, Russian Federation isachenko102@inbox.ru

Sevostyanova Irina Igorevna, Student

Prof. V.F. Voino-Yasenetsky Krasnoyarsk State Medical University

1, Partizan Zheleznyaka Str., Krasnoyarsk, 660022, Russian Federation Irisha94@inbox.ru

SPIN-code: $5745-3278$

ORCID: 0000-0002-9991-9062

ResearcherID: $K-7260-2018$ 